The geology of Tianshui-Qin'an area of the western Loess Plateau and the chemical characteristics of its Neolithic pottery

Hongjiao Ma, Anke Hein, Julian Henderson, Qinglin Ma

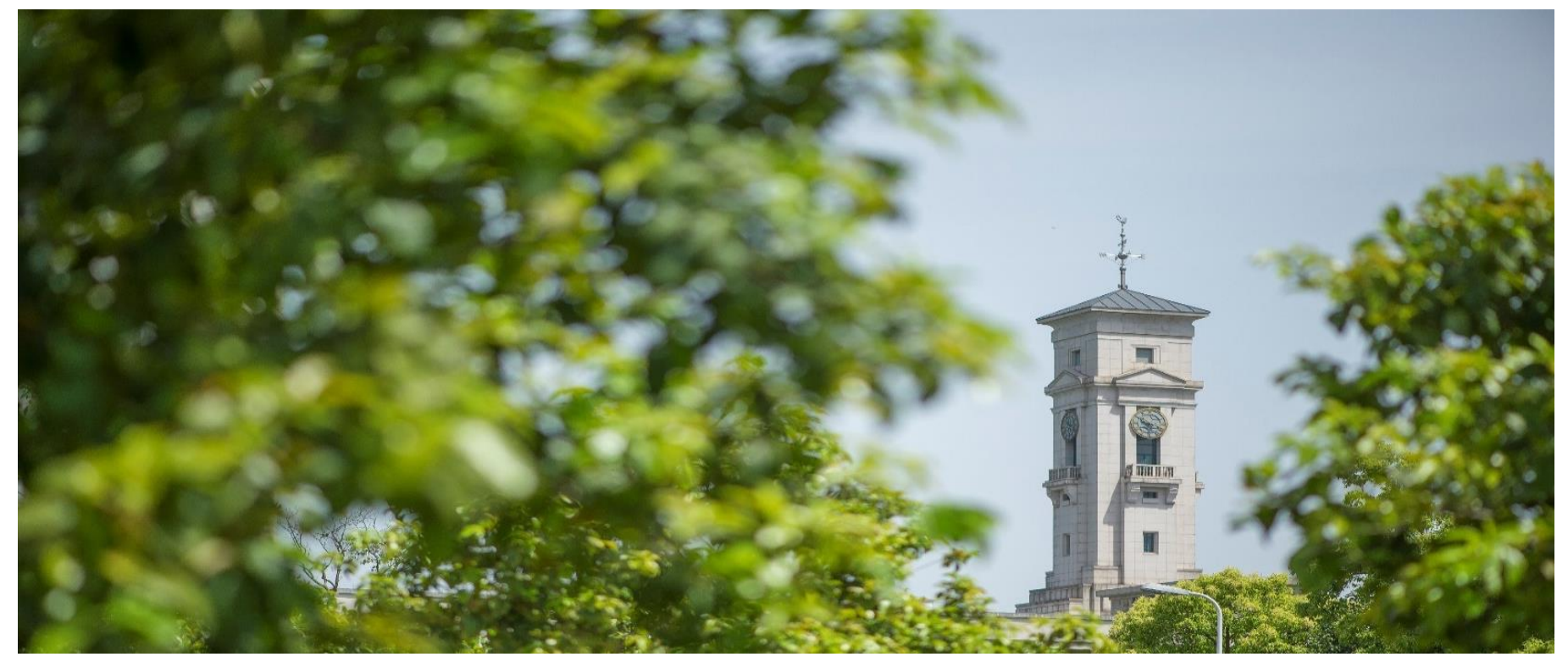


University of Nottingham Ningbo China, 199 Taikang East Road, Ningbo, 315100, Zhejiang, China.

First published 2020

This work is made available under the terms of the Creative Commons Attribution 4.0 International License:

http://creativecommons.org/licenses/by/4.0

The work is licenced to the University of Nottingham Ningbo China under the Global University Publication Licence:

https://www.nottingham.edu.cn/en/library/documents/researchsupport/global-university-publications-licence.pdf 


\title{
The geology of Tianshui-Qin'an area of the western Loess Plateau and the chemical characteristics of its Neolithic pottery
}

\author{
Hongjiao $\mathrm{Ma}^{1,2^{*}}$, Anke Hein ${ }^{3}$, Julian Henderson ${ }^{4,2}$, Ma Qinglin ${ }^{5}$ \\ 1. University of Science and Technology Beijing, Institute of Cultural Heritage and History of \\ Science \& Technology \\ NO.30 Xueyuan Road, Haidian District, Beijing, CN 100083 \\ 2. University of Nottingham - Ningbo China, School of international studies \\ 199 Taikang East Road, Ningbo, CN 315100 \\ 3. University of Oxford, Institute of Archaeology \\ Oxford, Oxfordshire, UK OX12PG \\ 4. University of Nottingham, Department of classics and archaeology \\ Nottingham, Nottinghamshire, UK NG7 2RD \\ 5. Shandong University, Institute of Cultural Heritage \\ Jinan, Shandong, CN 250100
}

\section{Conflicts of interest statement:}

The authors whose names are listed above certify that they have NO affiliations with or involvement in any organization or entity with any financial interest (such as honoraria; educational grants; participation in speakers' bureaus; membership, employment, consultancies, stock ownership, or other equity interest; and expert testimony or patent-licensing arrangements), or non-financial interest (such as personal or professional relationships, affiliations, knowledge or beliefs) in the subject matter or materials discussed in this manuscript.

\section{Data Availability Statement:}

The data that support the findings of this study are openly available in Nottingham Research Data Management Repository at http://doi.org/10.17639/nott.7025

\section{Abstract}

The difference in the chemical compositions between Neolithic pottery from the eastern and western ends of the northern Chinese Loess Plateau has been known for some time and a number of possible explanations have been proposed. However, a full understanding of the difference is yet to be achieved. Based on recent geological studies of the Tianshui-Qin'an area on the western Loess Plateau, the present study establishes a logical connection between the chemical characteristics of Neolithic pottery from the western Loess Plateau and the primary sediments available in the area. Moreover, this study reveals that the chemical compositions of clay used for fine wares and coarse wares at Dadiwan also bear some clear differences. Based on these findings, the paper discusses possible clay selection methods by potters in the Neolithic

\footnotetext{
* Correspondence author: Hongjiao Ma, email address: mahongjiao@ustb.edu.cn
} 
western Loess Plateau to make their different wares based on the locales where suitable raw materials are available. The paper demonstrates that the raw materials available for pottery making on the eastern and western Loess Plateau differ significantly and this explains the marked difference in ceramic composition between the two locations.

Key words: Neolithic pottery; Chinese Loess Plateau; Miocene loess-soil sequence; Geology; Ceramic technology

\section{Introduction}

Neolithic painted pottery from northern China is famous for its high quality and its aesthetic appeal. It has been a main focus of Chinese Neolithic archaeology. As it occurred mainly on the Loess Plateau, northern China forms the centre of the story for Chinese painted pottery. Painted pottery dating to the Neolithic period occurs in other parts of China as well, but much less commonly and with a rather different repertoire of shapes and decorations. Thus, the focus of this article will be on the materials from the Loess Plateau and its immediate surroundings.

Chinese painted pottery was first discovered and established as a research subject by Anderson in 1921. After a century-long enquiry of this material, our understanding of the origin, development, and transmission of Chinese Neolithic painted pottery and the cultural and social elements associated with it have greatly improved. So far, traditional typological approaches have been the main methods used in these studies, and the papers taking a scientific approach to technical aspects account for but a small fraction of the endeavour of understanding Neolithic pottery from both a technological and a cultural perspective. Nevertheless, even this comparatively small number of scientific studies on the topic have yielded important insights but also raised a number of new research questions and issues yet to be resolved. The present paper addresses one of them in particular, the question of why there are major differences in the chemical composition of the Neolithic painted wares from the western and the eastern part of the Loess Plateau. Based on comparative chemical analyses of ceramics from the Neolithic site of Dadiwan, clays retrieved from various locales around the site, and raw materials used in modern reproductions of Neolithic pottery, this paper also addresses a number of other research questions: What was the raw material chosen by Neolithic potters at this site? Was the same type of clay used for different types of wares or were several clay sources exploited? And most importantly what were the reasons for the potters choosing specific raw materials over others?

To situate these questions within their overall context, this paper commences with a review of previous scientific studies of Chinese Neolithic painted pottery with a focus on the understandings of raw material choice and preparation. Beyond addressing the research questions outlined above, the review will also serve as a concise and sorely needed English-language introduction to the history and current state of research on Chinese Neolithic painted pottery with a major focus on questions of technology and production, since studies of Chinese Neolithic pottery in English are not widely available. 


\section{History and Current State of Research}

Chinese Neolithic painted pottery was first discovered by Anderson in 1921 at Yangshao village, Henan Province. Incited by his European colleagues who suggested a connection with painted pottery traditions in Turkmenistan, in order to trace the origin of Chinese painted pottery, Anderson went west and found technologically even more sophisticated painted ceramics in Shannxi and Gansu Provinces. Although the assumption of a far western origin for Chinese painted pottery has been disproven, Anderson's endeavours led to the discovery of the main distribution area of Chinese Neolithic painted pottery and established the study of painted pottery as a major theme in Chinese archaeology. The first chemical composition of Chinese painted pottery was reported by Liang Siyong as part of the pioneering archaeological practice in China: the excavation and study of Xiyin site, Shanxi Province in 1920-30s (Liang 1996). The Swedish geologist Nils Sundius was the first to notice that the yellow-bodied painted pottery from Gansu Province had a higher $\mathrm{CaO}$ content than contemporary red-bodied painted pottery from Yanshao, Henan Province (Sundius 1961). Zhou Ren et al. (1964) published a paper entitled 'Studies on the technology of Neolithic and Yin and Chou pottery unearthed in the Yellow River Valley'. The main conclusion of this paper was that the primary loess from the Chinese Loess Plateau and the Yellow River Basin did not serve as raw materials for pottery making during the Neolithic, Shang and Zhou dynasties because of its high CaO content and poor plasticity; instead, the paper argued that it was probably the red clay and fine fluvial secondary loess along the rivers that were chosen by the early potters in this region. Zhou Ren's conclusions were confirmed by a number of studies which successfully recreated Neolithic ceramics using these two types of clay (Li 1984, Li et al. 1996). In these studies the term Quaternary red clay was used to refer to the red clay found on the Loess Plateau. However, as Wang et al. (2015) have pointed out, 'Quaternary red clay' is a potter's term while the more accurate geological term is Quaternary paleosols.

During the 1970s to 1990s, the main research endeavours on Chinese Neolithic painted pottery were concentrated on reconstructing the temporal and spatial framework of their distribution using typological approaches. Important studies in that vein, such as 'the origin of painted pottery in Gansu' by Yan Wenming (1978), established that Chinese Neolithic painted pottery first emerged in northern China and spread westward to Gansu and Qinghai Provinces and further west into Central Asia, leading to the development of several local varieties of painted pottery.

Ma Qinglin and his colleagues carried out a systematic survey of the chemistry of the Neolithic pottery from Gansu. The two resulting papers published in 1991 and 2004 reported the chemical composition of 25 pottery sherds from various Gansu Neolithic sites and 44 pottery sherds from various periods of the Neolithic Dadiwan site (Ma and Li 1991, Ma et al. 2004). Nearly $80 \%$ of the sherds analysed have a $\mathrm{CaO}$ content of more than $4 \mathrm{wt} \%$. The early Yangshao period fine pottery from Dadiwan was the only group with a higher proportion of wares containing low calcium than high calcium contents, and Ma Qinglin tentatively suggested the low calcium contents may have been the result of clay levigation (Ma et al. 2004). Hong Lingyu (written "Hung Ling-yu" in English-language publications) and her colleagues analysed 108 Neolithic pottery sherds of various periods from five sites in Gansu Province and found that a high $\mathrm{CaO}$ content was a 
common feature for nearly all of them. Based on the high $\mathrm{CaO}$ content of these samples, Hong Lingyu suggested that Tertiary red clay may have been the raw material used for Gansu Neolithic pottery because it contains a calcium content often over $10 \mathrm{wt} \%$ and it is also the red clay used by modern potters in Gansu (Hong et al. 2011). Cui Yifu and colleagues also pointed out that Neolithic painted pottery from Majiaoyao and Qijia cultural sites of eastern Qinghai Province (i.e., the western periphery of the Loess Plateau) also mostly have a Ca content of 4-12 wt\%, and Tertiary red clay was possibly the raw material source (Cui et al. 2015, Cui 2016). In contrast to 'Quaternary red clay', 'Tertiary red clay' is an established geological term. In geological studies, it is the term used to describe the continuous deposited sediment often overlain by Quaternary loess on Chinese Loess Plateau (Flynn et al. 2011).

In addition to Liang Siyong and Zhou Ren's early research on the chemistry of Neolithic pottery from the eastern part of the Loess Plateau, a few recent papers reported results from various sites. These include the chemical compositions of 32 samples from the Longshan period Pingtou site, Hequ, Shanxi Province (Wang et al. 2015), 61 samples from the Longshan period Xipo site, Lingbao, Henan Province (Lu et al. 2003), 14 samples from Dagujie site, Yulin, Shannxi Province (Rong, 2013), 116 samples from various sites in the Huanqu Basin, Shanxi Province (Wang 2014) and 125 samples from various sites in the Linfen Basin, Shanxi Province (Wang 2014). Figure 1 shows that nearly $80 \%$ of samples from these eastern Loess Plateau sites have a low $\mathrm{CaO}$ content of less than $3 \mathrm{wt} \%$. Quaternary red clay has been suggested as the main raw material for painted pottery wares from the Loess Plateau in a number of studies, sometimes mistakenly, but it was Wang Xiaojuan who attributed the Quaternary clay to its proper geological term 'paleosols' and pointed out that low $\mathrm{CaO}$ contents was a distinguishing chemical feature for this type of clay (Wang et al. 2015). Wang et al. (2015) also analysed ceramic raw materials found at the Pingtou site and paleosols samples from the nearby Quaternary 'red band' strata. The trace element chemical composition of these samples confirmed that Quaternary paleosols 'red clay' was very likely the raw material for the low calcium eastern Loess Plateau Neolithic pottery.

Based on these studies, it is clear that on the western side of the Loess Plateau in Gansu and Qinghai Provinces, Neolithic pottery was made mostly of clay containing $\mathrm{CaO}$ around $10 \mathrm{wt} \%$, and Neolithic pottery from the eastern side of the Loess Plateau had low calcium content (Figure 1). The suggestion made by Hong Lingyu that the 'red clay' used in Gansu and Qinghai was geologically different from the Quaternary paleosols 'red clay' used in the east and - based on its elevated calcium content - came from geological Tertiary red clay seems plausible (Hong et al. 2011). But why should this be the case? Why were different raw materials used on two sides of the Loess Plateau if the painted pottery had the same technological origin and occurred within the same landscape, i.e., with access to the same range of raw materials? Are there differences in the geology between the eastern and the western part of the Plateau after all, or are differences attributable to conscious technical choices? Moreover, what about the fluvial secondary clay mentioned by Zhou Ren and other potters; is this, too, a raw material used by Neolithic potters? In the present study, Neolithic pottery samples collected from the Dadiwan site, Qin'an County, Gansu Province were studied in order to address these questions.

\section{Samples}


The pottery samples studied in this research are Neolithic wares from five periods from Dadiwan (Table 1). Twenty-nine Neolithic Dadiwan pottery samples were provided by the Archaeological Institute of Gansu Province, and they were selected from the shard collection of the Dadiwan excavation with the help of an archaeologist from the excavation to confirm that they were the typical samples of each period. Nine of the samples are coarse pottery wares with visible inclusions, and the remaining twenty are fine pottery wares without visible inclusions; the samples include grey pottery, red pottery and black-painted pottery with a red or yellow base colour. Three pottery samples, QDTG4(3)10, QDTG4(3)11 and QDTG4(3)2Q3D, are low calcium painted wares of the second period (early Yangsho period) of Dadiwan from the same sample collection used by Ma et al. (2004). The reason why these three samples were chosen was to see if their trace element composition shows a noticeable difference from the high calcium samples.

Pottery sherds and raw materials collected from a modern potter in Qin'an who produces imitations of Neolithic painted pottery were also analysed. The raw materials used by the potter were collected from the paleosols strata in Kangpo village, Qin'an County. Two fine fluvial secondary loess samples collected on the bank of Hulu River, which runs by Dadiwan site, were also studied to see if they were possible candidates for Dadiwan Neolithic ceramic clays.

\section{Analyses}

Beyond recognizing the difference in $\mathrm{CaO}$ levels revealed by chemical analysis of Neolithic wares from the eastern and western part of the Loess Plateau, past endeavours using major and minor chemical compositions to study Chinese Neolithic pottery did not identify further chemical groups related to the geographical distribution of the wares. This could be due to the overall homogeneity in major and minor chemical compositions of Aeolian Chinese loess and the slight heterogeneity of different layers of paleosols derived from the loess through different degree of pedogenesis (Liu 1985).

In this study, we use trace element analysis as the main research technique for the clay component of our pottery samples. The use of trace element analysis is the common research approach to Chinese loess studies. There are also trace element data available from geological studies of Chinese loess to compare our results with.

The 21 reported trace elements of the samples were analysed quantitatively at the laboratory of Beijing Research Institute of Uranium Geology using Thermo Scientific Element XR high resolution ICP-MS system following the national standard method for chemical analysis of trace elements of silicate rock samples GB/T 14506.30-2010. The precision of all the analysed trace elements can be expected to be at 2-5 RSD\%. The accuracy of the analysis was monitored by analysing secondary standard, GBW07104 (Andesite reference material) and GBW07312 (Fluvial sediment reference material) in parallel multiple times during the analysis. The reference value, average measured value and relative deviation for each element of the two standards are listed in Table 3.

A preliminary thin section petrology study was carried out for the nine coarse pottery samples, mainly to assess how the sieving process should be conducted to best separate the coarse 
inclusions from the clay matrix. According to the thin section images (Figure 2) the coarse inclusions in the samples all have a bimodal distribution with the smaller inclusions with a size of 50-100 $\mu \mathrm{m}$ and bigger inclusions with a size of over $200 \mu \mathrm{m}$, and the small quartz particles within the clay matrix are with a size around $20 \mu \mathrm{m}$. Therefore, a set of three standard sieves, US mesh 100 (pore size $150 \mu \mathrm{m}$ ), US mesh 200 (pore size $75 \mu \mathrm{m}$ ) and US mesh 300 (pore size $53 \mu \mathrm{m}$ ), were used for separating the clay component of the coarse pottery sample from the coarse inclusions, a procedure that guarantees a thorough separation of the clay components without introducing obvious contamination from the coarse inclusion.

A semi-quantitative major and minor elemental analysis of studied samples was carried out using Shimadzu EDX-8000 energy dispersive X-ray fluorescence spectrometer and the results are reported in Table 2. Small fragments of each studied samples were mounted on epoxy resin and polished $0.25 \mathrm{~mm}$ diamond paste finish for the XRF analysis. The analysis was run using the fundamental parameter method provided by the manufacture under the following condition. For elements from Al-U, the X-ray was set to acceleration voltage of $50 \mathrm{KV}$ and current intensity of $200 \mu \mathrm{A}$; for element from C-Cs, the X-ray was set to acceleration voltage of $15 \mathrm{KV}$ and current intensity $500 \mu \mathrm{A}$. A collimator size $10 \mathrm{~mm}$ was used, and the spectrum was collected for 120 second in a vacuum chamber.

\section{Results}

The semi-quantitative survey of the major and minor elemental composition of the samples analysed in this study confirmed that the majority of fine pottery samples have a high $\mathrm{CaO}$ content of above $5 \mathrm{wt} \%$. Only one fine pottery sample from the first period and five fine pottery samples from the second period of Dadiwan have a CaO content of below 5 wt\% (1Q QDH379-1, 2QXN Q:DH717-1, 2QHT Q:DF209-1, QDTG4(3)10, QDTG4(3)11, QDG4(3)2Q3D), and the last three samples are the low calcium painted pottery samples from Ma et al. (2004). The chemical compositions of coarse pottery samples are more variable and do not show a pattern. This is probably due to the presence of coarse inclusions within the samples. The chemical compositions of possible raw materials collected at Qin'an, paleosols used by the modern potter and fine fluvial secondary loess, confirm that they both have high calcium contents.

The results for 21 trace elements for the clay component of the samples analysed in this study is reported in Table 4. A principal component analysis was carried out on the 21 elements for 37 samples. The main reason for conducting principal component analysis was to reduce the variables in a dataset to a manageable number of principal components while keeping most of the variance from the original dataset, so further analysis, such as comparing and plotting, could be done using the principal components instead of the original variables. Three principal components, which account for $76.4 \%$ variance of the original 21 x 37 dataset, were extracted and used for further analysis in this study.

From the variable loading plots of the principal components (Figure 3C, Figure 3D), it can be 
noticed that 18 out of 21 elements have high correlation with the principal component No.1 (correlation with PC1 >0.5), so groups differentiated by PC1 differ chemically in relation to the 18 elements. Sr and Ba have a high positive correlation with principal component No.2 (PC2), while $\mathrm{Bi}, \mathrm{Tl}$ and $\mathrm{Pb}$ have a relatively high negative correlation with $\mathrm{PC2}$, so groups picked up by $\mathrm{PC2}$ differ chemically in relation to these five elements. $\mathrm{Cu}$, $\mathrm{Co}$ and Sc have comparatively high negative correlation with principal component No.3 (PC3), so the groups showing differences on PC3 should differ compositionally in relation to the three elements.

Two scatter plots based on component scores of PC1 \& PC2 and PC1 \& PC3 of our samples are displayed in Figure $3 \mathrm{~A}, 3 \mathrm{~B}$, and groupings can be identified in the plots. In these figures, two groups mainly composed of fine pottery samples (group A) and coarse pottery samples (group B) respectively are clear to see according to their difference on PC1. The fine fluvial secondary loess samples and Qin'an paleosols used as modern pottery raw materials also cluster with the two groups respectively.

The three low calcium early Yangshao period Dadiwan painted pottery samples analysed in Ma et al. (2004) cluster with neither group A nor group B in Figure 3A, and two of the three samples cluster with neither group A nor group B in Figure 3B. This suggests the raw materials used for making these low calcium fine pottery wares from early Yangshao period of Dadiwan are different from other common wares of the site. Two coarse pottery samples also from early Yangshao period Dadiwan (2QJS Q:DH717-1 and 2QJS Q:DH717-3) do not cluster with other coarse pottery samples in group $B$, but plot within the ellipse of group $A$ in Figure $3 \mathrm{~A}$ and separate from all other samples with some distance in Figure $2 \mathrm{~B}$. This also suggests the raw materials used for making these two coarse wares were peculiar.

\section{Discussion}

\subsection{The different raw materials used for Neolithic Dadiwan fine pottery and coarse pottery}

The groups identified by principal component plots are one major discovery of this study. In the plots, the fine fluvial secondary loess and Qin'an local paleosols used as raw materials by modern potters group respectively with most Dadiwan coarse pottery samples and fine pottery samples, and this grouping suggests Neolithic Dadiwan potters may have used different raw materials for their coarse wares and fine wares.

Comparing the average trace element compositions of samples from group A and group B directly with that of Qin'an Miocene red clay as standardi (Liang et al. 2009), it can be seen that the average trace element composition of samples from group $A$ shows a very good agreement with Qin'an Miocene red clay paleosols, while the average trace element composition of samples from group B shows a clear discrepancy for most elements (Figure 4). This result agrees with our PCA result that there are distinctions for most elements between group $A$ and group $B$.

Similar chemical differences have been found in studies comparing fluvial secondary loess deposits, such as slack water deposits of Yellow river with paleosols (Huang et al. 2012, Zhang et 
al. 2015). It has been suggested that the distinctions were mainly the result of the 'dilution effect' of the higher component of coarse silt (grain size of 16-60 $\mu$ ) in fluvial secondary loess deposits (Huang et al. 2012).

To explain these differences, a more detailed description of the nature of fluvial secondary loess needs to be given here as background information. Unlike Tertiary red clay and Quaternary paleosols 'red clay' which are old soils developed from Aeolian loess through pedogenesis during the late Cenozoic, fluvial secondary loess is the re-deposited loess sediments which had been eroded from the Loess plateau (Zhang et al. 2015). The Yellow River and its tributaries wash down over $\mathbf{4 0 0}$ million tons of silt and sand from the Loess Plateau every year. A fraction of the eroded loess is redeposited in slack water areas along the rivers to form fluvial secondary loess. The fluvial secondary loess had gone through natural levigation by river water so the very fine grain portion is normally deposited on the surface layer and the very sandy portion on the bottom (Zhang et al. 2015).

On the one hand, it is not difficult to imagine that the raw materials for Dadiwan Neolithic fine pottery were likely to have been local paleosols, simply because paleosols are commonly available raw materials on the Loess plateau and they have the right physical and chemical quality for making fine pottery wares. Paleosols are the natural choice for modern potters living on the Loess Plateau today, and they have long been suggested as the raw materials for fine Neolithic and Bronze age pottery wares found on the Loess Plateau. Only one high calcium fine pottery ware (5QXN Q:DH5001) has been identified as an exception, according to the plotting it seems that it is more likely to have been made using fine fluvial secondary loess. On the other hand, the suggestion that fine fluvial secondary loess may also have been used, mainly for coarse ware, is a comparatively new insight gained in this study. Zhou Ren et al. (1964) pointed out that fine fluvial secondary loess could have been a possible candidate for ancient pottery from the Loess Pleateau and Li Xiangsheng (1984) created replicas of Neolithic pottery using this material. However, it has never been suggested in case studies of archaeological material that fine-grain fluvial secondary loess may have been used as raw material.

Another very important issue regarding the raw material used for Dadiwan coarse wares is whether the visible inclusions, which have been sieved out before the clay component is analysed, were added intentionally as temper during the material preparation or if they were natural inclusions from the fluvial secondary loess. The usual suggestion when a good bimodal distribution of coarse inclusions is seen in thin-section is that they were temper added to the clay during preparation (Quinn 2013). However, according to petrographic studies of fine fluvial secondary loess, it should have a matrix of big sub-rounded quartz and feldspar inclusions with sizes of between $60-400 \mu \mathrm{m}$ spreading like phenocrysts in the background of fine particles with size round $20 \mu \mathrm{m}$ (Liu 1966). This description fits the thin-section images of most of our coarse pottery samples although metamorphic rock fragments are also visible in samples 2QJS Q:DH717-1 and 2QJS Q:DH717-3, which are coarse pottery samples from early Yangshao period. Furthermore, with a few exceptions the inclusions are mostly sub-rounded or rounded, suggesting that they were a natural part of the raw material rather than added artificially by the potter. 
Therefore it seems that the technique of making Neolithic coarse pottery at Dadiwan was different from what we thought before. Previously, it was assumed that Neolithic potters used the same clay for coarse wares and fine wares, and the tempers in coarse wares were added deliberately during preparation (Liu et al. 1996). Instead, they may have used a different material, which naturally has higher percentage of coarse silt as well as large inclusions, for their coarse wares.

Further studies of more Neolithic coarse samples from different sites need to be carried out to see if different raw materials of fluvial origin were used for making coarse pottery, but identifying this as a possibility, as has been done here, is already a meaningful start.

\subsection{Did Neolithic potters on the western Loess Plateau really use Tertiary red clay as their raw material for fine pottery? If so, what were their reasons for choosing this particular raw material?}

Based on the analytical results presented here and the discussion above, we know that a type of paleosols was the raw material used to make Neolithic Dadiwan fine ware but possibly not for the coarse wares. The question remains: what was the geological nature of the paleosols used by Neolithic Dadiwan potters and modern Qin'an potters. Was it really Tertiary red clay as Hong Lingyu suggested? If it was, why is the nature of the paleosols used on the western Loess Plateau different from the paleosols used on the eastern Loess Plateau? No previous study has tried to explain it.

It is easy to understand and accept that Quaternary paleosols were the primary raw material commonly used by Neolithic eastern Loess Plateau potters as Wang Xiaojuan and many other scholars have suggested (Wang et al. 2015), because the Chinese Loess Plateau is thickly covered by loessic sediments composed of alternating strata of Quaternary Aeolian loess and derived paleosols (Liu 1985). On the section of any loessic hill on the Loess Plateau 'red bands' can be seen. These 'red bands' are paleosols derived from Quaternary Aeolian loess during the warmer and more humid climate of the interstadials (Liu 1985). Quaternary paleosols are a common raw material to which ancient potter had easy access. The Tertiary red clay, however, is deeply overlain by the Quaternary loess sequences. Although the continuous red layer of Tertiary red clay can occasionally be seen in the sections of some loessic hills (for instance at places where rivers cut through them), it was not as easily accessible as Quaternary paleosols. Then why would Neolithic potters on the western Loess Plateau have chosen this deeply buried clay over the easily accessed Quaternary paleosols?

It was the high calcium content of Neolithic pottery from the western Loess Plateau (Gansu and eastern Qinghai) that led scholars to suggest that Tertiary red clay was the raw material for these wares. It is a reasonable but incomplete deduction because other than Tertiary red clay, the fluvial secondary loess is also a high calcium raw material suitable for pottery making, and we have shown above that it was possibly this fluvial secondary loess rather than the Tertiary red clay that served as the raw material for the Dadiwan Neolithic coarse pottery. 
Even the close resemblance between the chemical compositions of Dadiwan fine pottery samples and the Qin'an Miocene red clay paleosols is not impeccable proof for the claim that Neolithic Dadiwan potters used local Tertiary red clay for their fine pottery because trace element compositions of all Chinese Aeolian loess and its derived paleosols are alike (Liang et al. 2009). The very similar trace element compositions of Quaternary loess and Tertiary red clay were one of the main points used to argue that similar to the Quaternary loess - Tertiary red clay also has an Aeolian origin (Guo et al. 2002). Therefore, in order to test whether Neolithic Dadiwan potters did use Tertiary red clay as the raw material for their fine pottery, evidence other than chemical composition needs to be found.

According to recent geological studies, the Tertiary red clay deposit on the western Loess Plateau, an area between the Liupan Mountains and the Tibetan Plateau covering one-fifth of the Loess Plateau, is quite different from its eastern counterpart (Guo et al. 2002). Because the general knowledge of the Chinese Loess Plateau was largely acquired by studying samples from the eastern Loess Plateau, the different geology of the western Loess Plateau was not reported until the early 2000s. Related studies show that, unlike the Tertiary red clay deposits on the eastern Loess Plateau which generally date prior to $8 \mathrm{Ma}$, the Tertiary red clay deposits on the western Loess Plateau are normally older than $11 \mathrm{Ma}$ and can be as old as $22 \mathrm{Ma}$ at many locations (Hao and Guo 2007). To distinguish it from the eastern Tertiary red clay which has a Pliocene date, the western red clay is more frequently referred to as Miocene red clay. The Aeolian origin of western Miocene red clay has been argued based on various pieces of evidence (Guo et al. 2002). Although Miocene red clay also had an Aeolian origin, unlike Quaternary loess it was formed during much more humid and warmer climate, nearly all Miocene red clay went through a certain degree of pedogenesis and the paleosols are continuously being formed (Hao and Guo 2007).

Qin'an County where Dadiwan site is located lies at the heart of the western Loess Plateau, also happens to be the place where the most typical Miocene sections studied by geologists are found. The topography of this area (Figure 5) is characterized by valleys flanked by elongated hills with thick and relatively flat sedimentary sequences deposited on metamorphic bedrock of early Palaeozoic age. The thick sedimentary sequences are mostly Miocene in date with the Quaternary loess only forming a mantle on hill tops of around $30 \mathrm{~m}$ thickness (Yuan et al. 2007).

The characteristics of the topography of Qin'an and the distribution of Miocene red clay there are keys to understanding why this 'red clay' was chosen by Dadiwan potters over Quaternary paleosols. The 'red clay' availability in Qin'an is very different from that on the eastern Loess Plateau. Miocene red clay was the most common 'red clay' available to the Neolithic potters in the area, and the Quaternary paleosols were less common by far.

Although not the entire western Loess Plateau was covered by this Tertiary deposit, it is not just limited to Qin'an County. According to recent geological studies, in the Tianshui-Qin'an area, this same topography covers an area stretching over hundreds of kilometres (Figure 1). In the Northwest, it reaches over $\mathbf{2 4 0 0} \mathrm{m}$ in altitude at the bedrock platforms of Huajialing County; in the South, it reaches the piedmont highlands of the West Qinling Mountain in Li County and Xihe 
County; in the East, it reaches altitudes of $1400 \mathrm{~m}$ at the slope of Liupan Mountain in Langzhuang County (Yuan et al. 2007). To the west of this area, the loessic deposits are slightly different, yet thick Miocene-Pliocene red layers are also commonly found. Northwest of the Tianshui-Qin'an area in the Linxia Basin, Tertiary red layer of some $400 \mathrm{~m}$ thickness commonly lies beneath Quaternary loess (Fang et al. 2007). Linxia Basin is the place where the later phases of the Majiayao culture are most commonly represented.

Further west at the western edge of the loess distribution area near the meeting point of the Tibetan Plateau and Loess Plateau in East Qinghai Province, Miocene red clay deposits dating to $14 \mathrm{Ma}$ are commonly found in high-grade terrace land along the Huangshui River (Lu et al. 2004). This area in East Qinhai Province lies within the distribution area of the Majiayao culture. The terraces along the Huangshui River have Neolithic settlements characterized by typical Majiayao painted pottery. Therefore, we can say that basically all the high calcium Neolithic ceramics occurring on the western Loess Plateau are found within the area where the Tertiary red layers are widely available and could have been accessed by Neolithic potters. Tertiary red layers may thus have been used commonly by western Loess plateau Neolithic potters.

\subsection{The anomalies shown in early Yangshao period Dadiwan pottery samples and their possible explanation}

Qinglin Ma reported that high proportions of low calcium fine pottery wares were found only among the early Yangshao period Dadiwan samples, and he tentatively interpreted this anomaly as the result of the artificial removal of impurities by hand sorting and/or levigation of the clay (Ma et al. 2004). In the present study, three low calcium painted pottery fine ware samples from the early Yangshao layers at Dadiwan used in Ma et al. (2004) were analysed for their trace element compositions, and they do not cluster with high calcium fine pottery wares from Dadiwan in group A in our principal component plots. So they are chemically slightly different from most other fine pottery wares in Dadiwan. However the reason for their compositional difference is probably not physical refinement by levigation and other methods as these do not reduce the calcium concentrations in loessic clay (Zhou et al. 1964). The calcium concentration in the fine clay component of loessic clay is as high as that in the whole rock, so physical refinement may result in finer clay but it will not reduce the calcium concentration of the clay (Liu 1966).

Other than the slightly different chemistry found in these early Yangshao period Dadiwan fine wares, two coarse pottery samples (2QJS Q:DH717-1 and 2QJS Q:DH717-3) also show different chemistry from other coarse pottery samples from Dadiwan and they contain inclusions not seen in any other samples. Is it possible that these anomalies found in early Yangshao period samples from Dadiwan may be a variety of pottery that we did not identify in other periods due to the numbers of samples examined?

Early Yangshao is the time when Yangshao material culture first emerged at Dadiwan site and when the settlement grew significantly. Given that ceramics were of great importance in everyday life as well as in ritual acts, as their occurrence in large number in burials as well as settlement contexts shows, the appearance of a new type of pottery is a major indicator of 
cultural changes, be it through local developments or through outside contact. Given that the Yangshao type pottery predating the Dadiwan finds was found in large number at sites further east, it is generally accepted that here cultural influences via migration and/or various types of contact and exchange took place. Therefore these early Yangshao wares with slight anomalies in chemistry and temper inclusions from other common Dadiwan pottery wares may not have been made at Dadiwan but perhaps were transferred from their place of manufacture via migration or exchange.

As only very few studies of Chinese Neolithic pottery from Loess Plateau have used trace element analysis or thin section petrography, it is still not possible to suggest the geographical or geological origins for these peculiar samples from early Yangshao period layers of Dadiwan due to the lack of comparable published materials with definite provenance. Even the very well developed typological approach of Chinese Neolithic archaeology is unable to suggest any more than the early Yangshao ceramic types of Dadiwan came from somewhere in the east. However, if more geological and geochemical studies of Chinese Neolithic pottery are accumulated, to be able to suggest the path of cultural exchange should eventually become possible.

\section{Conclusion}

As became clear from the discussion above, this study has made some progress toward identifying the raw material sources used in the production of Neolithic pottery on the western Loess Plateau; furthermore, some suggestions for the reasons behind these choices have been made. The present study shows that at Dadiwan, possibly both paleosols 'red clay' and fine fluvial secondary loess were used simultaneously but for different types of wares, one for fine ware, the other for coarse ware. The latter may not have been tempered with sand or crushed rock as previously assumed but they may have been made of naturally coarse material available on the river banks.

Another much-debated issue for which this paper has provided new insights is the question about which type of 'red clay' the potters at Dadiwan used. Most previous studies have concentrated on geological sequences and archaeological evidence from the eastern Loess Plateau, arguing convincingly that the widely available Quaternary paleosols was generally used for producing Neolithic pottery wares. Although it has been suggested that Tertiary red clay may have been the primary raw material for pottery wares made on the western Loess Plateau, the line of argument and evidence for such a suggestion has turned out to be weak, and the poor accessibility of Tertiary red clay for Neolithic potters has made the suggestion less credible. Based on recent geological studies, this paper shows that the geology and raw materials available for fine pottery making on the eastern versus the western Loess Plateau are rather different, and the Miocene red clay was the most commonly available clay in the west and the logical choice for Dadiwan Neolithic potters for their fine wares. This example has made it abundantly clear that localized geological observations are crucial in establishing the range of possible clay sources which can then be compared to actual archaeological ceramics. 
By considering the archaeological context, this paper has also presented a sensible explanation for the seemingly peculiar pottery assemblage found only in the early Yangshao layers at Dadiwan: they were manufactured in a different geological context, where the Yangshao type material culture originally came from. Their presence during the early Yangshao period at Dadiwan is another piece of evidence for the suggested migration of Yangshao culture from further east, though the precise origin remains unclear.

This paper has thus clearly shown that it is crucial to combine information on local geology, insights from contemporary pottery practices, comparative analysis of both archaeological ceramics and presumed raw materials, and other archaeological information such as ceramic styles and migration histories to gain an accurate understanding of past raw material choices and their underlying reasons.

\section{Acknowledgement}

This work was supported by the National Natural Science Foundation of China (Grant No.51802017). The authors are indebted to the Archaeological Institute of Gansu Province for providing samples from pottery ware collection of archaeological excavation of Dadiwan site. Special gratitude is also paid to Dr. Elisabeth Steer for her help on thin-section petrography.

\section{References}

[dataset] Ma, H., Hein, A., Henderson, J., Ma, Q., Steer, E.; 2019; The geology of Tianshui-Qin'an area of the western Loess Plateau and the chemical characteristics of its Neolithic pottery; Nottingham Research Data Management Repository; http://doi.org/10.17639/nott.7025

Cui, Y., 2016. Early ceramic trade and its influence factors during late Neolithic in Gansu-Qinghai region 甘青地区新石器时代晚期陶器贸易及其影响因素初步研究. Master dissertation, Lanzhou University.

Cui, Y., Dong, G., Li, H., An, T., Liu, X., Wang, J., Wang, H., Ren, X., Li, X. and Chen, F., 2015. Early ceramic trade in Gansu and Qinghai regions, northwest China: A comparative elemental analysis on sherds of Majiayao culture, Yangshao culture and Qijia culture. Journal of Archaeological Science: Reports. 3, 65-72.

Fang, X., Xu, X., Song, C., Han, W., Meng, Q., and Masayuki, T., 2007. High Resolution Rock magnetic records of Cenozoic sediments in the Linxia Basin and their implications on drying of Asian inland. Quaternary Sciences, 27(6), 989-1000.

Flynn, L.J., Deng, T,. Wang, Y., Xie, G., Hou, S., Pang, L. and Mu, Y., 2011. Observations on the Hipparion Red Clays of the Loess Plateau. Vertebrata PalAsiatica. 49(3), 275-284.

Guo, Z.T., Ruddiman, W.F., Hao, Q.Z., Wu, H.B., Qiao, Y.S., Zhu, R.X., Peng, S.Z., Wei, J.J., Yuan, B.Y. and Liu, T.S., 2002. Onset of Asian desertification by $22 \mathrm{Myr}$ ago inferred from loess deposits in China. Nature, 416(6877), 159-163.

Hao, Q. and Guo, Z., 2007. Magnetostratigraphy of an early-middle Miocene loess-soil sequence in the western Loess Plateau of China. Geophysical Research Letters, 34(18).

Hong, L., Cui, J., Wang, H., and Chen, J., 2011. A provenance study of Majiayao painted pottery found in western Sichuan Province 川西马家窑类型彩陶产源分析与探讨. South Ethnology and 
Archaeology 南方民族考古.7, 1-58.

Huang, C. C., Pang, J., Zha, X., Zhou, Y., Su, H., Zhang, Y., Wang, H. And Gu, H., 2012. Holocene palaeoflood events recorded by slackwater deposits along the lower Jinghe River valley, middle Yellow River basin, China. Journal of Quaternary Science, 27(5), 485-493.

Li, W., 1996. A study of the pottery-making technology in ancient China 中国古代制陶工艺研究. Science Press, Beijing.

Li, W., Lang, S., and Zhang, J., 1996. The study of pottery craft during the first period of Dadiwan site, Qin'an 甘肃秦安大地湾一期制陶工艺研究. Archaeology and Cultural relics 考古与文物. (2), 23-35.

$\mathrm{Li}, \mathrm{X}$., 1984. Some insights about the clay, manufacturing crafts and artistic values of colour painted pottery of Yangshao culture 试析仰韶文化彩陶的泥料、制作工艺、轮绘技术和艺术. Cultural Relics of Central China 中原文物. (1), 53-59.

Liang, M., Guo, Z., Kahmann, A.J. and Oldfield, F., 2009. Geochemical characteristics of the Miocene eolian deposits in China: their provenance and climate implications. Geochemistry, Geophysics, Geosystems, 10(4).

Liang, S., 1996. The study of the neolithic pottery from Xyincun pre-historical archaeological site 山西西阴村史前遗址的新石器时代的陶器. Sanjin Archaeology 三晋考古. 2, 287-324.

Liu, D., 1966. The mineralogical composition and structure of loess 黄土的物质成分和结构. Science Press, Beijing.

Liu, D., 1985. Loess and environment 黄土与环境. Science Press, Beijing.

Lu, H., Wang, X., An, Z., Miao, X.D., Zhu, R.X., Ma, H.Z., Li, Z., Tan, H.B. and Wang, X.Y., 2004. Geomorphologic evidence of phased uplift of the northeastern Qinghai-Tibet Plateau since 14 million years ago. SCIENCE IN CHINA (SERIES D EARTH SCIENCES, ENGLISH EDITION), 47, 822-833. Lu, X., Li, W., Luo, H., Zhao, J., Li, Xinwei., Ma, Xiaolin., and Yang, H., 2011. A scientific study of pottery wares from Xipo archaeological site, Lingbao County, Henan 河南灵宝西坡遗址陶器的 科技研究, in: Centre for Archaeological Science, Institute of Archaeology, Chinese Academy of Social Science (Eds.), Science for Archaeology, Vol.3 科技考古（第三辑）. Science Press, Beijing， 203-212.

Ma, Q., and Li, X., 1991. The study of pottery crafts of different cultural periods in Gansu 甘肃古 代各文化时期制陶工艺研究. Kaogu 考古. (3), 263-272.

Ma, Q., Su, B., Hu, Z., and Li, Z., 2004. Chemical analysis of pottery wares unearthed at Dadiwan Neolithic site of Qin'an County, Gansu Province 甘肃秦安大地湾遗址出土陶器成分分析. Kaogu 考古. (2), 86-93.

Quinn, P.S., 2013. Ceramic petrography. The interpretation of archaeological pottery and related artefacts in thin section: Oxford, Archaeopress.

Rong, B., Yang, L., Ma, M., Zhao, J., and Wang, C., 2013. Study of the Yangshao painted potteries excavated in Dagujie remains of Hengshan County 榆林横山大古界遗址出土仰韶晚期陶器的 科学分析. Sciences of Conservation and Archaeology 文物保护与考古科学, 25(3), 82-87.

Sundius, N., 1961. Some aspects of the technical development in the manufacture of the Chinese pottery wares of pre-Ming age. Bulletin of the Museum of Far Eastern Antiquities. 33, 103-124.

Wang, X., 2014. The Research on the Pottery Industry of Neolithic Later Periods in Jinna area 晋 南地区新石器末期陶器工业. PhD thesis, Peking University.

Wang, X., Nan, P., and Guo, Y., 2015. Chemical analysis of pottery and clay raw materials from the Longshan period at the Pingtou site in Hequ County, Shanxi Province 河曲坪头遗址龙山时期陶 
器及其制陶原料的化学成分分析. Sciences of Conservation and Archaeology 文物保护与考古 科学, 27(4), 61-69.

Wen, Q., Diao, G., and Geng, An,. 1989. The Geochemistry of Chinese Loess 中国黄土地球化学. Science Press, Beijing

Yan, W., 1978. The origin of colour painted pottery from Gansu 甘肃彩陶的源流. Wenwu 文物. (10), 62-76.

Yuan, B.Y., Guo, Z.T., Hao, Q.Z., Peng, S.Z., Qiao, Y.S., Wu, H.B., Xiao, G.Q., Ge, J.Y., Sun, B., Zhou, X. and Yin, Q., 2007. Cenozoic evolution of geomorphic and sedimentary environments in the Tianshui-Qin'an regions. Quaternary Sciences, 27(2), 161-171.

Zhang, Y., Huang, C. C., Pang, J., Zha, X., Zhou, Y. and Wang, X., 2015. Holocene palaeoflood events recorded by slackwater deposits along the middle Beiluohe River valley, middle Yellow River basin, China. Boreas, 44(1), 127-138.

Zhou, R., Zhang, F., and Zheng, Y., 1964. Studies on the technology of Neolithic and Yin and Chou pottery unearthed in the Yellow River Valley 我国黄河流域新石器时代和殷周时代制陶工艺的 科学总结. Acta Archaeologica Sinica 考古学报 . (1), 1-27.

\footnotetext{
i The composition of Sr is not compared with data from Liang et al. (2009), because different preparation methods were used in the two studies. All the carbonate inclusions from samples of Liang et al. (2009) had been removed using $1 \mathrm{~mol} / \mathrm{l}$ acetic acid before acid dissolution of samples to eliminate the influence of carbonate translocation. Therefore the chemical compositions of elements such as $\mathrm{Ca}$ and $\mathrm{Sr}$ were significantly changed from the whole rock composition because carbonate contain high contents of $\mathrm{Ca}$ and Sr. The original contents of $\mathrm{Ca}$ and $\mathrm{Sr}$ are very important values to investigate in current study, so carbonate inclusions were not removed before analysis.
} 